\title{
EXPLOSIVENESS OF HYDROCARBON VAPOURS IN INDUSTRIAL INSTALLATIONS UNDER VARIOUS CONDITIONS
}

\author{
JAN KARL ${ }^{1}$, ELIŠKA FIŠEROVÁ ${ }^{1} \&$ DANIEL MAXA ${ }^{2}$ \\ ${ }^{1}$ Research and Development Department, Technical Institute of Fire Protection in Prague, \\ Fire and Rescue Service of the Czech Republic, Czech Republic \\ ${ }^{2}$ Department of Petroleum Technology and Alternative Fuels, \\ University of Chemistry and Technology Prague, Czech Republic
}

\begin{abstract}
Cleaning, maintenance and repair works in petroleum transport and storage equipment are activities connected with an increased risk of explosion. After the pipes and vessels have been emptied, residual amounts of flammable liquids can spontaneously evaporate into the equipment vapour space. To appraise the risk of explosion, it is necessary to assess the formation of an explosive mixture of hydrocarbons with air under various operating conditions. A device was designed that simulates the described system at a reduced scale under stationary conditions for which a vapour-liquid equilibrium is reached. The equilibrium gas phase was analysed to determine the influence of temperature, pressure, and initial liquid phase volume proportion on the lower explosion limit percentage value. The results of the experiments were compared with numerical calculations. Aspen HYSYS software was used for theoretical calculations of vapour-liquid equilibrium and estimation of the lower explosive limit percentage value. It has been confirmed that the concentration of flammable substances in the mixture increases with temperature. As expected, the concentration of flammable substances at a certain temperature decreased with increasing pressure, as the partial pressure of flammable substances remained approximately the same at elevated partial pressures of air. The prediction of the vapour phase composition based on equilibrium calculations in the process simulator provided a pessimistic estimate of the results with a higher hydrocarbon concentration than the experimental measurements. Since the theoretical estimate of the composition of the hydrocarbon-containing atmosphere was always on the "safe side", it seems to be suitable for predicting the risk of explosion in industrial facilities under known conditions - temperature, pressure, composition and amount of flammable substance.

Keywords: explosive limits, hydrocarbon vapours, petroleum.
\end{abstract}

\section{INTRODUCTION}

One of the most important aspects in the processing and handling of flammable substances in the oil industry is safety. Increased probability of explosion risk is associated with shutdowns and cleaning work in oil transport areas. In these situations, residual amounts of flammable liquids in the piping or storage vessels spontaneously evaporate into the released volume of the device. It is therefore necessary to assess the risk of formation of an explosive hydrocarbon/air mixture in a confined space under different conditions.

A device was created that simulated, for example, a shutdown petroleum pipeline, or other storage facilities in which residual amounts of petroleum could be present. Since it is almost practically impossible to carry out laboratory measurements in a continuous system simulating, for example, petroleum extraction from pipelines, a device has been proposed that simulates such a system at a reduced scale in a quiescent phase. The dependence of the lower explosion limits percentages under different conditions was determined by gas phase analyses. The results of the experiments were compared with numerical calculations. 


\section{FIRE HAZARD IN FACILITIES}

The safety of operations, persons and the environment in situations involving the handling of petroleum, natural gas, petrochemical products and other flammable substances during outages, cleaning and repairs of technological equipment is an important topic in recent years. The information gathered from accident studies is now being used to implement various measures in many facilities. Examples of the accidents studied that led to further research needs include disaster Piper Alpha and Buncefield.

Disasters were able to stir scientific attention to focus on fire and explosion hazards. New studies have begun to address deficiencies such as passive fire protection [1], standard fire tests [2], efficiency of water sprays protecting LPG pressure tanks [3], fire tests for internal and external heat flow and internal temperature stages [4], [5] and many others. Emergencies such as disasters have always given impetus to new studies and needs to eliminate emerging danger.

The draft of explosion tests and their parameters should reflect real conditions in industrial installations based on real process requirements and needs. For example, a description of the pipeline inerting process and safety assessment using high pressure technology is given in [6].

\subsection{Computational estimates of explosive concentration limits}

Three basic conditions must be met, namely the provision of a flammable substance at a suitable concentration, an oxidizing agent and an ignition source.

In particular, two main approaches are used for numerical estimation of explosive limits of flammable substances. The first group of methods for estimating explosive limits studies the composition of mixtures and is based on the values of explosive limits of pure substances in relation to the composition of the mixture. The second part of the estimates treats the mixture as an individual substance and evaluates it on the basis of molecular composition and stoichiometry of combustion reactions.

2.1.1 Empirical estimation from the composition of the substance

The calculation of the explosion limits is based on the calculation of the stoichiometric concentration of the combustible in the mixture with air $c_{s t}$ from the equations of combustion (1)-(3)

$$
\begin{gathered}
C_{x} H_{z} O_{y}+m_{2} \rightarrow x C O_{2}+\frac{y}{2} H_{2} O, \\
c_{s t}=\frac{n_{\text {fuel }}}{n_{\text {fuel }}+n_{\text {air }}} \cdot 100, \\
c_{s t}=\frac{100}{1+\frac{m}{0.21}},
\end{gathered}
$$

where $c_{s t}=$ stoichiometric composition, $n_{\text {fuel }}=$ number of moles of fuel (mol), $n_{\text {air }}=$ number of moles of air (mol), $m=$ stoichiometric oxygen coefficient, $0.21=$ oxygen content in the air (vol. \%) [7].

From the calculated stoichiometric concentration, the lower (LEL) and upper (UEL) explosion limits can then be calculated according to eqns (4) and (5) [7]

$$
\begin{gathered}
L E L=0.55 c_{s t}, \\
U E L=3.5 c_{s t} .
\end{gathered}
$$


2.1.2 Calculation of explosion limits of mixtures

Another possibility for numerical estimation of the explosion limits is based on equations

$$
\begin{aligned}
L E L_{\text {mix }} & =\frac{1}{\sum_{1}^{n} \frac{y_{i}}{L E L_{i}}}, \\
U E L_{\text {mix }} & =\frac{1}{\sum_{1}^{n} \frac{y_{i}}{U E L_{i}}},
\end{aligned}
$$

where $L E L_{m i x}=$ lower explosion limit of a mixture of flammable gases, $L E L_{i}=$ lower explosion limit of the pure component, $U E L_{m i x}=$ upper explosion limit of a mixture of flammable gases, $U E L_{i}=$ lower explosion limit of the pure component, $y_{i}=$ volumetric $/ \mathrm{molar}$ fraction of the pure component.

Eqns (6) and (7) were defined by Le Chatelier [8]. They utilize the values of explosive concentration limits of pure substances which are in the mixture. A disadvantage is the necessary knowledge of the explosion limits of the individual components of the mixture.

Preconditions are: constant heat capacity of products, similar adiabatic temperature heating, similar combustion kinetics.

\subsubsection{Phase equilibrium}

In the event that the flammable mixture is due to the partial evaporation of the liquid material, it is necessary to describe the vapour-liquid phase equilibrium to determine the gas phase composition with the risk of explosion.

When analysing the equilibrium state of a system describing a device with a residual liquid combustible content, it is generally necessary to determine:

1. the amount of coexisting phases at the moment of reaching equilibrium; and

2. equilibrium composition of phases.

Given initial conditions (usually temperature, pressure, volume and initial composition of the liquid and gaseous phases) must be taken into account in the calculations.

There are many methods available to describe vapour-liquid equilibrium (VLE), which must be always selected with respect to the composition of the flammable liquid.

2.1.4 Vapour-liquid equilibrium in multicomponent systems for real behaviour The relation between vapour and liquid phase is given by equation

$$
\varphi_{i}^{V} y_{i}=\varphi_{i}^{L} x_{i}
$$

where $\varphi_{i}$ with indexes $V$ and $L$ are fugacity coefficients for vapour and liquid phases, respectively, $y_{i}=$ molar fraction of component in vapour phase, $x_{i}=$ molar fraction of component in liquid phase.

Fugacity coefficients can be obtained from the equation of state. Since the invention of the Van der Waals equation, many variants of semiempirical VLE equations have been proposed.

One of the most successful modifications was made by Redlich and Kwong [9]. Both gaseous and liquid phases were described by state equation using fugacity coefficient $f$. It is a universal method applicable to high-pressure equilibria, gas solubility, etc.

The activity models handle highly non-ideal systems and are much more empirical in nature when compared to the property predictions in the hydrocarbon industry. Polar or non-ideal chemical systems are traditionally handled using dual model approaches. In this type of approach, an equation of state is used for predicting the vapour fugacity coefficients 
and an activity coefficient model is used for the liquid phase. Since the experimental data for activity model parameters are fitted for a specific range, these property methods cannot be used as reliably for generalized applications [10].

In practice, these methods are used in computing software to describe VLE; it is then up to the user to select appropriate equations to describe the behaviour of a particular mixture of substances under given conditions. Great attention must be taken in the VLE assessment procedure, otherwise there may be significant deviations of calculated data from reality. An overview of some of the models used in Aspen HYSYS software, where they are part of socalled "fluid packages", is given in Table 1, including examples (substances in the mixture, thermodynamic conditions) of suitable use.

Table 1: Overview fluid packages used by HYSYS.

\begin{tabular}{|c|c|c|}
\hline $\begin{array}{l}\text { State model } \\
\text { fluid packages }\end{array}$ & Description & $\begin{array}{l}\text { Temperature } \\
\text { and pressure } \\
\text { conditions }\end{array}$ \\
\hline $\begin{array}{l}\text { Peng } \\
\text { Robinson }\end{array}$ & $\begin{array}{l}\text { Relatively accurate equilibrium calculations from } \\
\text { very low temperatures to high temperatures and high } \\
\text { pressures. Suitable from heavy oil fractions to } \\
\text { systems with methanol, glycols, acid gases and water. }\end{array}$ & $\begin{array}{l}\text { From }-271^{\circ} \mathrm{C} \\
\text { to } 100 \mathrm{MPa}\end{array}$ \\
\hline $\begin{array}{l}\text { Zudkevitch- } \\
\text { Joffee }\end{array}$ & $\begin{array}{l}\text { For more accurate calculations of hydrogen- } \\
\text { containing hydrocarbon systems. A modification of } \\
\text { the Peng Robinson equation. }\end{array}$ & $\begin{array}{l}\text { From }-271^{\circ} \mathrm{C} \\
\text { to } 100 \mathrm{MPa}\end{array}$ \\
\hline $\begin{array}{l}\text { Soave Redlich } \\
\text { Kwong }\end{array}$ & $\begin{array}{l}\text { Not suitable for systems with methanol or glycols, } \\
\text { usable in a smaller range of conditions. A } \\
\text { modification of the Peng Robinson equation. }\end{array}$ & $\begin{array}{l}\text { From }-143^{\circ} \mathrm{C} \\
\text { to } 35 \mathrm{MPa}\end{array}$ \\
\hline $\begin{array}{l}\text { Kabadi- } \\
\text { Danner }\end{array}$ & $\begin{array}{l}\text { It allows for more accurate equilibrium calculations } \\
\text { of water-containing three-phase systems, especially } \\
\text { in the low concentration range. A modification of the } \\
\text { Soace Redlich Kwong system of equations. }\end{array}$ & $\begin{array}{l}\text { From }-143^{\circ} \mathrm{C} \\
\text { to } 35 \mathrm{MPa}\end{array}$ \\
\hline $\begin{array}{l}\text { Peng } \\
\text { Robinson } \\
\text { Styjek-Vera }\end{array}$ & $\begin{array}{l}\text { As good (and better) results as PR, especially in non- } \\
\text { ideal systems where it competes with activity models. } \\
\text { It requires more processing power and an additional } \\
\text { interaction parameter (only a limited number of } \\
\text { component pairs). A modification of the Peng } \\
\text { Robinson equation. }\end{array}$ & $\begin{array}{l}\text { From }-271^{\circ} \mathrm{C} \\
\text { to } 100 \mathrm{MPa}\end{array}$ \\
\hline $\begin{array}{l}\text { Chao-Seader a } \\
\text { Grayson- } \\
\text { Streed }\end{array}$ & $\begin{array}{l}\text { A model for a three-phase system where the second } \\
\text { liquid phase is water. Used for streams consisting of } \\
\text { water and e.g. light hydrocarbons, or systems with } \\
\text { high hydrogen concentration. }\end{array}$ & Not specified \\
\hline $\begin{array}{l}\text { Models based } \\
\text { on vapour } \\
\text { pressure } \\
\text { calculation }\end{array}$ & $\begin{array}{l}\text { Suitable for working with heavier hydrocarbon } \\
\text { mixtures at lower pressures. They use the extended } \\
\text { Antoine equation to calculate the phase equilibrium - } \\
\text { extension to six coefficients. The equation covers } \\
\text { wide temperature and pressure conditions. }\end{array}$ & $\begin{array}{l}\text { According to } \\
\text { the Antoine } \\
\text { equation }\end{array}$ \\
\hline Active models & $\begin{array}{l}\text { It uses the vapour phase fugacity coefficient and the } \\
\text { liquid phase activity coefficient to calculate the } \\
\text { equilibrium coefficient. }\end{array}$ & Not specified \\
\hline
\end{tabular}


Two of the models in Table 1 were selected and used in the experimental part. The first model is Peng Robinson, which is described in the book: A new two-constant equation of state [11]. The second model is based on the vapour pressure calculation using the extended Antoine equation.

\section{EXPERIMENTAL SECTION}

A test sample of crude oil Russian Export Blend (REB) was chosen for this work. The oil was taken from the Družba pipeline in 2018 and was stored in a sealed tight container in a cool environment at all times to ensure the least possible change in composition.

\subsection{Test vessel}

The test vessel was designed for determination of the gas phase composition at crude oil-air equilibrium under variable temperature and pressure conditions. The aim was to simulate a shutdown crude oil pipeline or other enclosed spaces containing residual amount of crude oil. Since it is not possible to carry out laboratory measurements with continuous flow, a device has been proposed which simulates such a system on a reduced scale under stationary conditions.

The test device simulates a closed system with the presence of a residual amount of flammable substance to determine the equilibrium of the liquid and gaseous phases under different temperature and pressure conditions. The main part of the device is a $300 \mathrm{ml}$ pressure cylindrical stainless steel container fitted with a lid for emptying and cleaning. Inlets and outlets are located in the lid, enabling the supply of liquid sample and gas, pressure measurement and equilibrium gas phase withdrawal. A steel ball of approximately $1 \mathrm{~cm}$ diameter was placed in the vessel to ensure stirring. The device description is shown in Fig. 1.

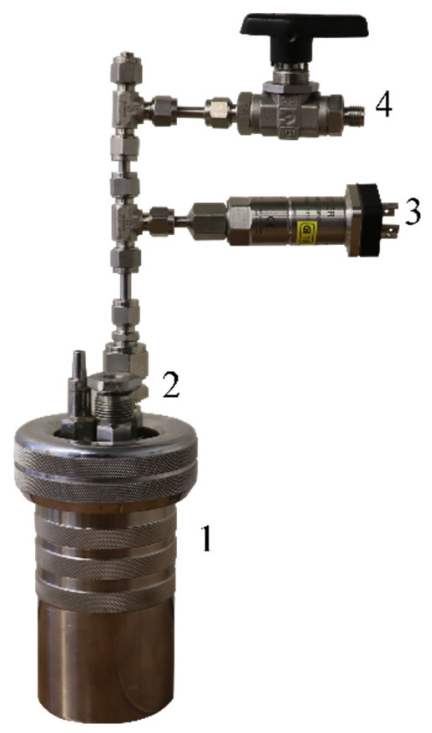

$$
\begin{aligned}
& 1=\text { test vessel } \\
& 2=\text { intlet for dosing of flammable } \\
& \text { liquid/ gas phase sampling } \\
& 3=\text { pressure sensor } \\
& 4=\text { stopcock and inlet for compressed } \\
& \text { air }
\end{aligned}
$$

Figure 1: Test vessel. 


\subsection{Experimental conditions}

Test conditions were chosen according to real conditions (see Table 2). The variables were temperature, pressure, and sample percentage in the test equipment volume. For each sample volume, the gas phase composition was determined experimentally under all temperature and pressure conditions listed below.

Table 2: Conditions for experimental determination.

\begin{tabular}{|c|c|c|}
\hline $\begin{array}{c}\text { Temperature } \\
\text { conditions }\left({ }^{\circ} \mathrm{C}\right)\end{array}$ & $\begin{array}{c}\text { Pressure } \\
\text { conditions }(\mathrm{kPa})\end{array}$ & $\begin{array}{c}\text { Liquid sample proportion } \\
\text { of the total volume }(\%)\end{array}$ \\
\hline 10 & 100 & 0.5 \\
\hline 20 & 150 & 1 \\
\hline 30 & 250 & 2 \\
\hline 40 & 500 & - \\
\hline
\end{tabular}

\subsection{Procedure to ensure equilibrium conditions and sampling}

The determination of the liquid-vapour equilibrium was carried out in the test vessel described in 3.1. A test liquid sample of the exact amount was dosed by a syringe into a test vessel at atmospheric pressure via inlet for dosing and sampling. After the sample was dosed, the device was sealed and, if necessary, connected to compressed air and filled with air to the required pressure. During equilibrium stabilization, the liquid mixture was stirred using a steel ball inside the test vessel for at two minute intervals to stabilize the equilibrium faster. After a minimum time of 20 minutes elapsed, a gaseous sample was taken from the test vessel using a $50 \mu \mathrm{l}$ gas-tight syringe and then the sample was analysed by gas chromatography. After the sample was taken for analysis, the vessel was removed from the bath, optionally depressurized, and subsequently cleaned with acetone and dried by compressed air.

After checking the functionality of the device, it was necessary to determine the time required to stabilize the equilibrium. According to the procedure described above, the composition of the gas phase with different sampling times was measured. Initial conditions were selected $T=20^{\circ} \mathrm{C}, p=100 \mathrm{kPa}$, liquid amount $=1 \%$ of vessel volume $(3 \mathrm{ml})$. A gas phase sample for analysis was taken at $10 \mathrm{~min}, 20 \mathrm{~min}, 40 \mathrm{~min}$ and $70 \mathrm{~min}$. After evaluation of these analyses the time for further measurements was determined. The minimum equilibrium time was set at $20 \mathrm{~min}$ (see Table 3).

Table 3: Evaluation of the time needed to stabilize the equilibrium.

\begin{tabular}{|l|c|c|c|c|c|}
\hline Time of sampling (min) & 10 & 20 & 40 & 40 & 70 \\
\hline Vol. \% flammable substance & 5.52 & 7.20 & 7.53 & 7.79 & 7.13 \\
\hline
\end{tabular}

The results of the gas phase analysis were converted to volume fractions of the individual components of the mixture. From the values of the lower explosive limit of the pure components [12], the theoretical lower explosive limit of the mixture of hydrocarbons in the vapour phase was calculated using eqn (6). From the theoretical lower explosion limit and the actual flammable concentration, the percentage of the lower explosion limit of the vapour-phase hydrocarbon mixture could be calculated, which could be compared with the calculated values using the estimates obtained from software Aspen HYSYS as described in Section 3.3. 


\subsection{Calculations}

Computational software for numerical simulations of technological processes Aspen HYSYS V 8.8 was used for theoretical calculations of equilibria and estimation of the percentage value of the lower explosive limit. Fig. 2 shows a proposed flow diagram that ensures mixing a liquid crude oil sample with air at a desired ratio and setting the required final temperature. The composition of equilibrium vapour and liquid phases is then monitored in the output streams.

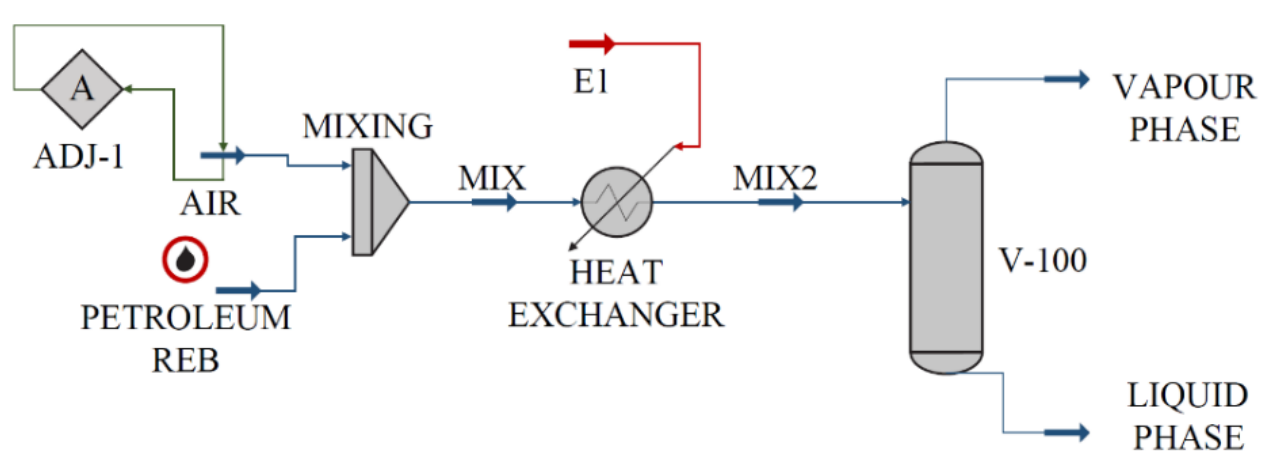

Figure 2: Scheme for computational estimation of liquid-vapour equilibrium.

Two different computational models ("Fluid packages") were used for the calculation Peng Robinson based on equation of state and model based on calculation of vapour pressure using the modified Antoine equation.

Extended Antoine Equation

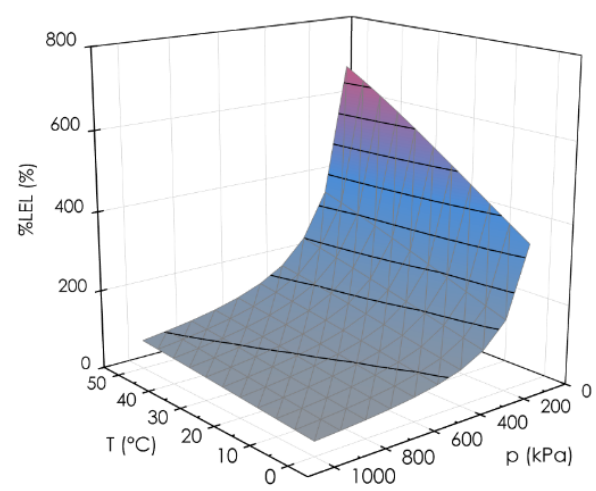

Peng Robinson

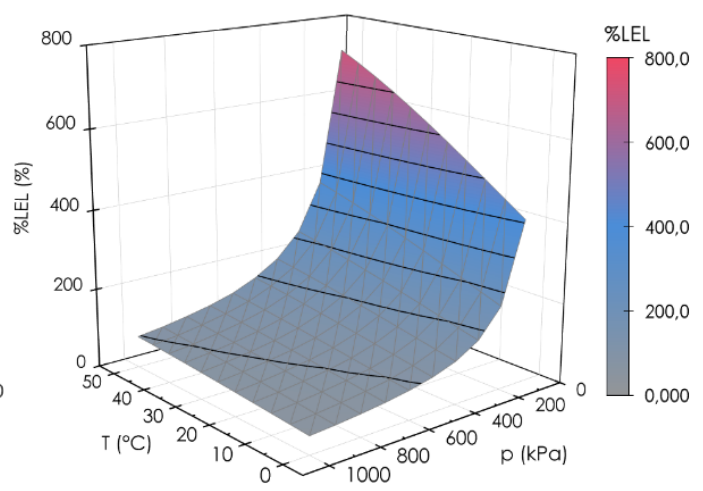

Figure 3: \% LEL values calculated using Extended Antoine Equation and Peng Robinson EOS fluid packages $(0.5 \%$ liquid sample in test vessel total volume). 
Extended Antoine Equation

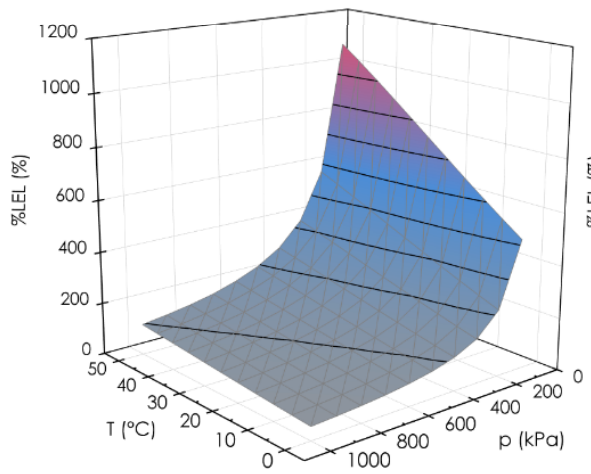

Peng Robinson

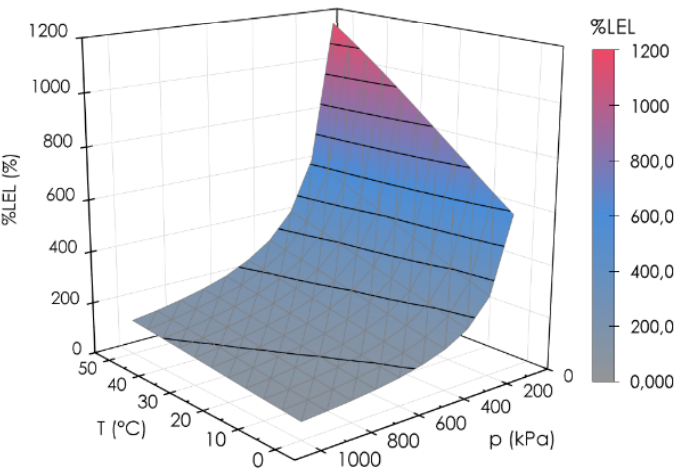

Figure 4: \% LEL values calculated using Extended Antoine Equation and Peng Robinson EOS fluid packages (1\% liquid sample in test vessel total volume).
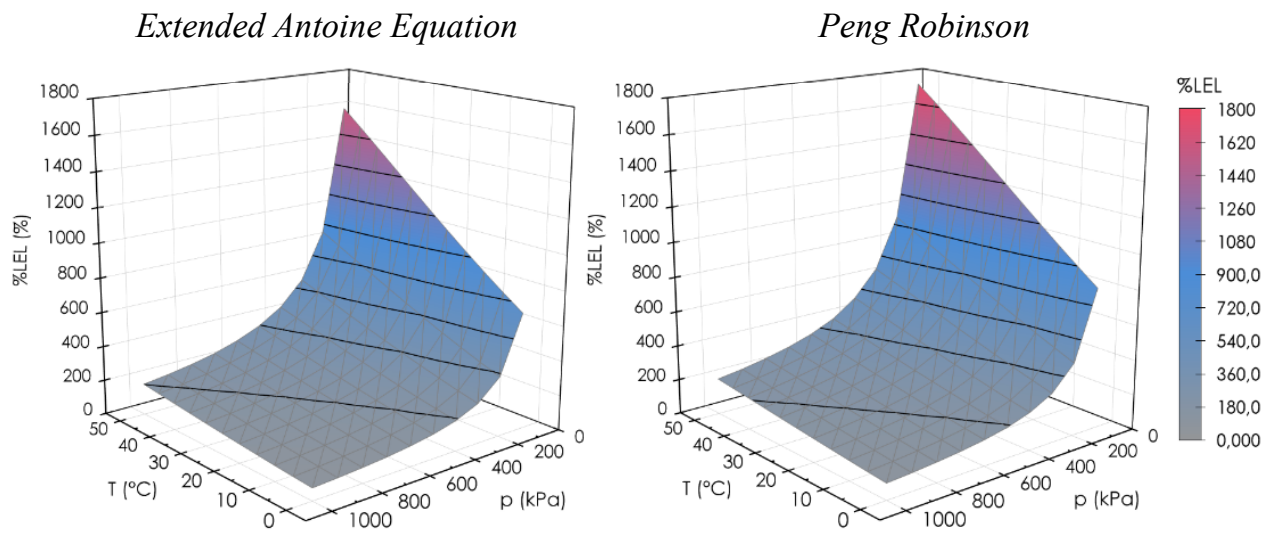

Figure 5: \% LEL values calculated using Extended Antoine Equation and Peng Robinson EOS fluid packages ( $2 \%$ liquid sample in test vessel total volume).

\section{RESULTS}

\subsection{The effect of initial conditions on calculated \% LEL}

The results of the calculations were evaluated as \% LEL depending on the temperature and pressure. Figs 3, 4 and 5 show the results of calculations using two "Fluid packages" Extended Antoine Equation and Peng Robinson model.

\subsection{Comparison of experimental LEL percentage results with calculated results}

The results obtained using the model based on the calculation of the vapour pressure from the extended Antoine equation were in better agreement with the experimental data than the results of the calculations with the Peng Robinson model. The comparison is shown in 
Figs 6, 7 and 8; for the sake of clarity in the graphs, the results from the Peng Robinson model calculations are not stated. The curves describe the change in \% LEL as a function of pressure at given temperature for different percentage of the liquid sample in the test vessel total volume.

Concentrations of flammable substances and thus also \% LEL values determined experimentally are lower than calculated ones in the whole studied temperature and pressure range while maintaining expected trends.

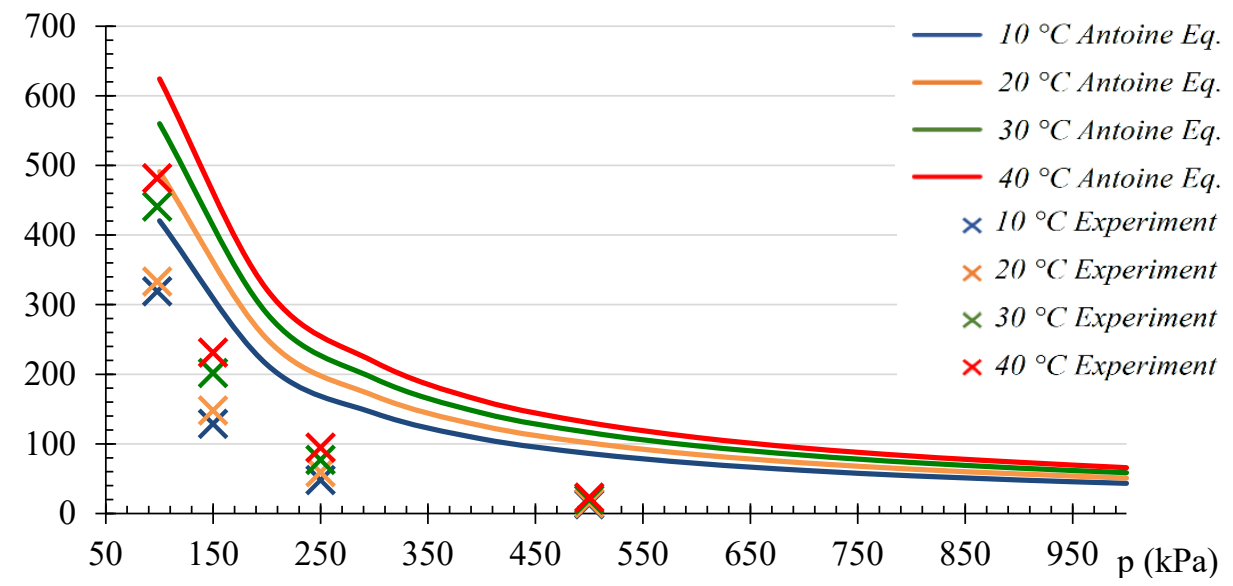

Figure 6: Comparison of calculated (Extended Antoine Equation) and measured \% LEL values for $0.5 \%$ liquid sample in test vessel total volume.

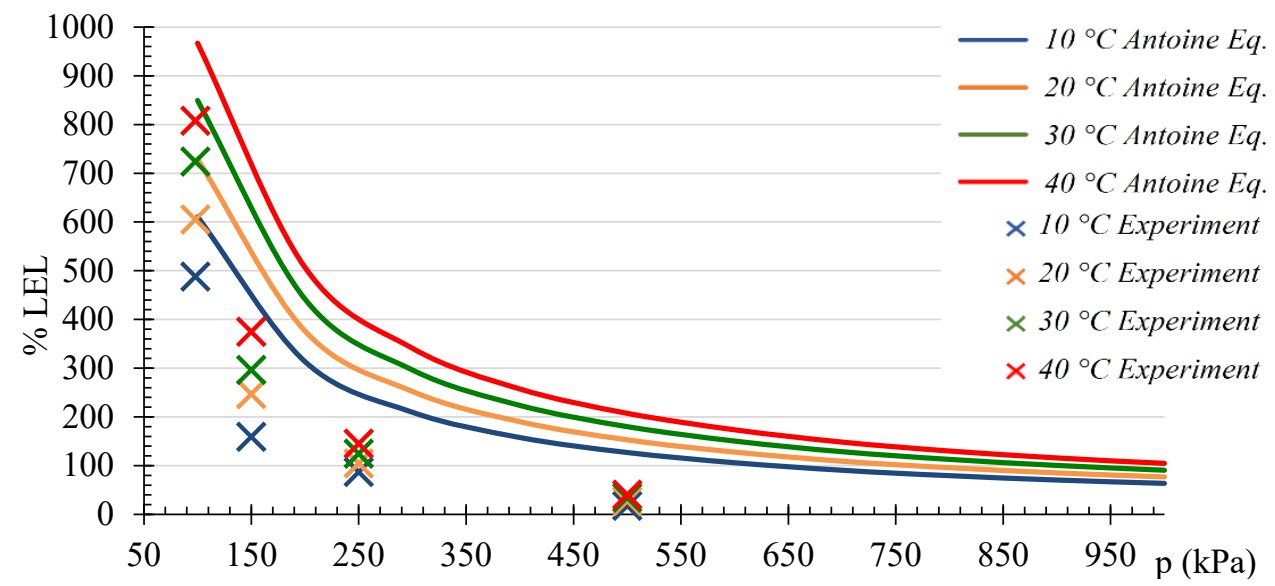

Figure 7: Comparison of calculated (Extended Antoine Equation) and measured \% LEL values for $1 \%$ liquid sample in test vessel total volume. 


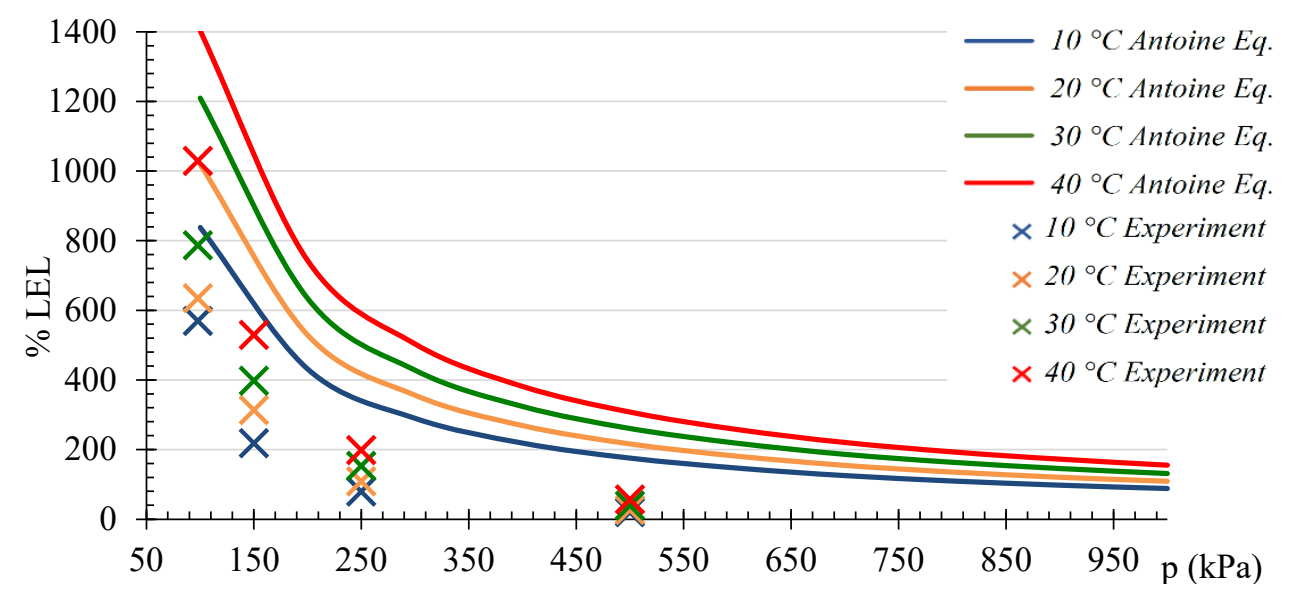

Figure 8: Comparison of calculated (Extended Antoine Equation) and measured \% LEL values for $2 \%$ liquid sample in test vessel total volume.

\section{CONCLUSIONS}

Concentrations of flammable substances were determined after stabilization of the liquidvapour equilibrium at varied temperature, pressure and percentage of the flammable liquid sample volume in a closed test vessel. The volume percentage of the liquid sample was estimated according to real conditions in industrial equipment during its shut-down and emptying prior to cleaning and maintenance work; $0.5,1$ and $2 \%$ of the device volume was selected. For identical conditions, the composition of the vapour phase was calculated using simulation software with different fluid packages. Based on the results of the composition of the gas phase, the danger of the formation of an explosive environment under different conditions was evaluated.

It has been verified that with increasing temperature the concentration of flammable substances in the mixture increases. The results using the computational model based on the calculation of the vapour pressure from the extended Antoine equation were in better agreement with the experimental data than the results of the calculations with the Peng Robinson model. Prediction of the vapour phase composition based on equilibrium calculations in the process simulator gave more pessimistic results - higher hydrocarbon concentrations - than experimental measurements. Based on this fact, it is possible to assume the suitability of equilibrium calculation for the prediction of explosion risk in industrial equipment under known conditions - the temperature, pressure, composition and the amount of liquid flammable substance that remains in vessels and pipes after the equipment has been shut down.

\section{REFERENCES}

[1] Shirvill, L.C., Performance of passive fire protection in jet fires. IChemE Symposium on Major Hazards - Onshore and Offshore, UMIST, Manchester, Symposium Series 13, pp. 111-122, 1992.

[2] BS ISO22899-1:2007, Determination of the Resistance to Jet Fires of Passive Fire Protection Material, Part 1: General Requirements, 2007.

[3] Shirvill, L.C., Efficacy of Water Spray Protection Against Propane and Butane Jet Fires Impinging on LPG Storage Tanks, Shell Global Solutions: UK, 2000. 
[4] Lowesmith, B.J., Hankinson, J., Acton, M.R. \& Chamberlain, G.A., An overview of the nature of hydrocarbon jet fire hazards in the oil and gas industry and a simplified approach to assessing the hazards. Process Safety and Environmental Protection, 85, pp. 207-220, 2007.

[5] Hankinson, G., Lowesmith, B.J., Evans, J.A. \& Shirvill, L.C, Jet fires involving releases of crude oil, gas and water. Process Safety and Environmental Protection, 85, pp. 221-229, 2007.

[6] Karl, J., Hussein, T., Maxa, D. \& Stukbauer, M., Inerting of Pipelines Containing of Complex Hydrocarbon Mixtures, ISHPMIE, Kansas City, USA, 2018.

[7] Zabetakis, M.G., Flammability Characteristics of Combustible Gases and Vapors, Washington, 1965.

[8] Kondo, S. et al., Extended Le Chatelier's formula and nitrogen dilution effect on the flammability limits. Fire Safety Journal, 41, pp. 406-417, 2006.

[9] Redlich, O. \& Kwong, J.N.S., On the thermodynamics of solutions. V. An equation of state: Fugacities of gaseous solutions. Chemical Reviews, 44, pp. 233-244, 1949.

[10] Property Package Descriptions. www.razifar.com/cariboost_files/Property_20 Package_20Descriptions.pdf. Accessed on: 10 Apr. 2020.

[11] Peng, D.Y. \& Robinson, D.B., A new two-constant equation of state. Chemical Engineering, 9, pp. 531-545, 1970.

[12] Brandes, E. \& Möller, W., Safety Characteristic Data: Volume 1: Flammable Liquids and Gases, 2008. 